\title{
Erice Call for Change: Utilising Patient Experiences to Enhance the Quality and Safety of Healthcare
}

\author{
Elena Rocca ${ }^{1}$ (D Rani Lill Anjum ${ }^{1}$
}

Published online: 15 April 2020

(c) The Author(s) 2020

\begin{abstract}
This 'Erice Call for Change' is a report from a group of experts, patients and patient representatives who met in Erice in September 2019 following previous similar meetings after the original Erice Declaration (1996). The aim of the meeting was to discuss the challenge of causal complexity and individual variation in modern healthcare. The group's concern was the impact that new clinical decision-making tools, based on statistical correlations in large databases, could have on individual patient care if they replace other types of clinical investigation and knowledge. The group calls for a change in the approach to the care of the individual patient, and indicates some specific challenges to overcome for such changes to happen.
\end{abstract}

\section{Introduction}

This document represents the collective opinion of 18 experienced, interested individuals who met in Erice, Sicily, in September 2019 to consider new perspectives in the conceptualisation of causality in clinical diagnosis and decision making.

\section{The Challenge of Causal Complexity and Individual Variation in Modern Healthcare}

The practice of healthcare is changing fast due to rapid developments in the socio-legislative area and in technology. New clinical tools are available in many countries, using artificial intelligence, large-scale databases, computer modelling and increasingly sophisticated statistical methods [1, 2]. While these changes have improved the scope and efficiency of medicine and healthcare, we are concerned about their impact on clinical decision making and individual patient care if they replace other types of clinical investigation and knowledge.

Healthcare professionals base their work on a body of knowledge. This includes theoretical knowledge about

Elena Rocca

elena.rocca@nmbu.no

1 Centre for Applied Philosophy of Science, Norwegian University of Life Sciences, Ås, Norway pathology, physiology, pharmacology, statistical correlations and other evidence of treatment effectiveness, as well as harms for both individuals and public health. However, this knowledge base alone does not necessarily generate the best clinical decisions and choices for an individual. It needs, in addition, to be evaluated in light of the unique and complex reality of the individual receiving care. How should this be done?

In pursuit of answers to this challenging question, the Erice meeting brought together a broadly experienced group of individuals that included scientific researchers, epidemiologists, clinicians, pharmacists, decision makers, drug manufacturers, communications specialists, patients and philosophers of science, each representing their own experience and perspective. The aim of the meeting was to draft a transdisciplinary approach to the following issues:

- How should clinical practice and research gather and utilise rich narratives of patients' individual experiences to improve general medical and therapeutic knowledge and patient safety?

- How can such narratives help inform and improve treatment decisions for each individual and for others?

\section{A United Call for Change}

The group calls for changes in medicine and healthcare: the aim is to unleash the potential for the best possible individual healthcare. While there is already some drive in the 
professions towards some of the changes proposed, the potential for improvement is still vast. This call for change sets out the direction in which healthcare should be moving.

\section{The Approach to Patient Care}

A genuinely person-centred healthcare must be protected and promoted. Mutually attentive engagement between patients and those providing their care plays a vital role. Healthcare must aim to treat the whole person, and not fall into the error of treating people just as examples of diseases and symptoms in a fragmented way. Person-centred healthcare that is also evidence-based must take account of the multiple causal mechanisms and contextual factors that can affect the treatment of a single patient in their unique circumstances.

Such person-centred healthcare should affect the thinking, decision making and practice not only of clinical healthcare professionals but also of researchers, managers and governmental authorities. They should consider more than just the normative data from controlled studies that are not likely to be generalisable to all individuals.

\section{Challenges}

How to ensure the humane and visionary purposes of traditional practice are not lost in an era of accelerating change: that the benefits of technology add to humane practices and individual health care.

How to ensure transparency of possible conflicts of interest (financial, religious, institutional, political, etc.) among clinicians and institutions that might affect their interpretation of causal evidence, their clinical decisions and their patients.

How to create more informal platforms for multidisciplinary networking, facilitating critical reflection and professional debate during the day-to-day activity of healthcare practitioners and researchers.

How to reconcile the public health interests of equality of care with optimal care for individuals, adapted to their personal needs. Interventions that benefit or harm the community as a whole will not necessarily benefit or harm each member of that community.

How to promote whole person care by overcoming the fragmentation and lack of coordination caused by a segmented healthcare system.

\section{Ensuring Best Outcomes of Patient Care}

Outcomes of therapy for all patients need to be improved: patients should feel they get the treatment that is most accurately tailored to their individual needs. To achieve this, there needs to be continuity of care, where a patient's journey along a timeline of events is the foundation of clinical investigation and review.

Causal considerations in patient safety, including drug safety and toxicity, must be focused on the particular individual by prioritizing rich qualitative narratives of their context, history and experience. Well-documented spontaneous adverse reaction reports with narrative are valuable but many have minimal information. Narrative reporting from these and other sources needs to be encouraged and enhanced. These patient narratives should be collected, analysed and used qualitatively in a practical, accessible system, in an agreed format that is compatible with high ethical standards so that they can be used as important qualitative evidence regarding causation.

Patients should be invited to take an active role in their own healthcare, characterised by genuinely collaborative and egalitarian communication. They can be empowered by participating in transdisciplinary networks, with healthcare professionals working to push current thinking forward.

\section{Challenges}

How to ensure the best treatment and care for all by overcoming the restrictions of a healthcare system in which time constraints, bureaucracy and cost efficiency drive practice.

How to make use of individual experiences in light of the current constraints of data protection policy, while at the same time managing important ethical issues regarding access, ownership, confidentiality and security of information.

How to promote the central concepts, such as risk, probability, causality, propensity (disposition) and complexity that need to be given greater attention by everyone, including researchers, clinicians, patients and decision makers.

How to improve the ways in which causality is understood, detected and evidenced for the purpose of individuals.

How to acknowledge and communicate that causal evidence is never complete or perfect. No matter how much general evidence is available, some uncertainty about causes and outcomes for individuals remains inevitable.

This call for change proposes re-evaluation of the values and practice of individual healthcare, and then action by the people, systems and priorities that drive and support it. We hope that it will provoke broader interest, commentary and action. 


\section{Promotors and Participants}

The meeting took place in Erice, Sicily, 13-14 September 2019, and was organised by the International School of Pharmacology at the Ettore Majorana Foundation, in collaboration with the Uppsala Monitoring Centre, Sweden and the NMBU Centre for Applied Philosophy of Science, Norway.

Participants were selected by the organising committee on the basis of their broad interest and expertise in the discussed topics and representing their own view from within academia, regulatory agencies, pharmaceutical industry, patient groups and clinical practice. Participants, in alphabetical order, were as follows.

Rani Lill Anjum, Norway; Jean-Christophe Delumeau, Singapore; Ivor Ralph Edwards, Sweden; Birgitta Grundmark, Sweden; Kai Brynjar Hagen, Norway; François Houÿez, France; Bruce Hugman, UK; Tobias Gustum Lindstad, Norway; Marie Lindquist, Sweden; Matthew Low, UK; Ugo Moretti, Italy; Eugenio Paci, Italy; Christine Price, UK; Elena Rocca, Norway; Lovisa Sandberg, Sweden; Ruth Savage, New Zealand; Penny Sawell, UK; Anders Sundström, Sweden.

\section{A Note on the Erice Process}

Giampaolo Velo was the visionary instigator and sponsor of the original Erice drug safety communication meeting in 1996. He, along with Ugo Moretti and Roberto Leone, members of his team at the University of Verona, as well as Ralph Edwards and Bruce Hugman, Uppsala Monitoring Centre, have been behind the whole series of Erice meetings [3-6], leading up to the current meeting that resulted in the Erice Call for Change (2020).

Acknowledgements Open Access funding provided by Norwegian University of Life Sciences.

Data sharing Not applicable to this article as no dataset were generate or analysed during the current study.

\section{Compliance with Ethical Standards}

Funding Uppsala Monitoring Centre Foundation and Ettore Majorana Foundation.

Conflicts of interest The authors declare that they have no conflicts of interest.

Open Access This article is licensed under a Creative Commons Attribution-NonCommercial 4.0 International License, which permits any non-commercial use, sharing, adaptation, distribution and reproduction in any medium or format, as long as you give appropriate credit to the original author(s) and the source, provide a link to the Creative Commons licence, and indicate if changes were made. The images or other third party material in this article are included in the article's Creative Commons licence, unless indicated otherwise in a credit line to the material. If material is not included in the article's Creative Commons licence and your intended use is not permitted by statutory regulation or exceeds the permitted use, you will need to obtain permission directly from the copyright holder. To view a copy of this licence, visit http://creativecommons.org/licenses/by-nc/4.0/.

\section{References}

1. Capobianco E. Data-driven clinical decision processes: it's time. J Transl Med. 2019;17:44. https://doi.org/10.1186/s1296 7-019-1795-5.

2. Melton BL. Systematic review of medical informatics-supported medication decision making. Biomed Inform Ins. 2017. https:// doi.org/10.1177/1178222617.

3. Bowdler J. The Erice declaration: on communicating drug safety information. Prescrire Int. 1998;7(38):191.

4. Velo GP, Hugman B. The Erice Manifesto: for global reform of the safety of medicines in patient care. Drug Saf. 2007;30(3):18790. https://doi.org/10.2165/00002018-200730030-00001.

5. Members of EMERGE, Erice Medication Errors Research Group, Agrawal A, Aronson JK, et al. Medication errors: problems and recommendations from a consensus meeting. Br J Clin Pharmacol. 2009;67(6):592-8. https://doi.org/10.111 1/j.1365-2125.2009.03414.x

6. Edwards IR. A new Erice report considering the safety of medicines in the 21st century. Drug Saf. 2017;40(10):845-9. https:// doi.org/10.1007/s40264-017-0571-9. 